\title{
Validity evidence for the Hamburg multiple mini-interview
}

\author{
Mirjana Knorr ${ }^{1 *}$ (D, Anja Schwibbe ${ }^{1}$, Maren Ehrhardt ${ }^{2}$, Janina Lackamp', Stefan Zimmermann ${ }^{1}$ \\ and Wolfgang Hampe ${ }^{1}$
}

\begin{abstract}
Background: Multiple mini-interviews (MMI) become increasingly popular for the selection of medical students. In this work, we examine the validity evidence for the Hamburg MMl.

Methods: We conducted three follow-up studies for the 2014 cohort of applicants to medical school over the course of two years. We calculated Spearman's rank correlation $(\rho)$ between MMI results and (1) emotional intelligence measured by the Trait Emotional Intelligence Questionnaire (TEIQue-SF) and the Situational Test of Emotion Management (STEM),

(2) supervisors' and practice team members' evaluations of psychosocial competencies and suitability for the medical profession after a one-week 1:1 teaching in a general practice (GP) and (3) objective structured clinical examination (OSCE) scores.

Results: There were no significant correlations between MMI results and the TEIQue-SF $(\rho=.07, p>.05)$ or the $\operatorname{STEM}(\rho=.05, p>05)$. MMl results could significantly predict GP evaluations of psychosocial competencies $(\rho=.32, p<.05)$ and suitability for the medical profession $(\rho=.42, p<.01)$ as well as OSCE scores $(\rho=.23, p<.05)$. The MMI remained a significant predictor of these outcomes in a robust regression model including gender and age as control variables.

Conclusions: Our findings suggest that MMls can measure competencies that are relevant in a practical context. However, these competencies do not seem to be related to emotional intelligence as measured by self-report or situational judgement test.
\end{abstract}

Keywords: Multiple mini-interviews, Psychosocial competencies, Selection of medical students, Admission, Emotional intelligence, General practice

\section{Background}

Current competency frameworks in medical education agree that medical students and future doctors need pronounced psychosocial competencies such as communication skills, self-regulation and perspective taking [1-3]. Interest in considering these competencies already during the student selection process is growing [4]. Among the variety of selection methods used in medical education, multiple mini-interviews (MMI) are gaining popularity because of the superior reliability compared to traditional interview formats [5]. The MMI is an assessment method similar to an objective structured clinical examination (OSCE): candidates rotate through a circuit of several short stations and

\footnotetext{
* Correspondence: m.knorr@uke.de

${ }^{1}$ Department of Biochemistry and Molecular Cell Biology, University Medical Center Hamburg-Eppendorf (UKE), N30, Martinistraße 52, 20246 Hamburg, Germany

Full list of author information is available at the end of the article
}

are assessed by one or two independent raters per station [5]. At each station, they usually respond to standardized questions or interact with a simulated patient. Unlike OSCEs, which primarily assess clinical skills, MMIs typically do not require the application of clinical skills or knowledge [5]. MMIs can be adjusted to specific objectives and therefore they differ among institutions in design and target competencies [6]. Three systematic reviews on MMIs have concluded that feasibility and internal reliability of MMIs are well researched and, amongst other points, that future research should focus more on validity evidence [6-8]. In this work, we describe the Hamburg MMI for undergraduate entry into medical school and summarise the first validity evidence for an MMI in a German context.

(c) The Author(s). 2018 Open Access This article is distributed under the terms of the Creative Commons Attribution 4.0 International License (http://creativecommons.org/licenses/by/4.0/), which permits unrestricted use, distribution, and reproduction in any medium, provided you give appropriate credit to the original author(s) and the source, provide a link to the Creative Commons license, and indicate if changes were made. The Creative Commons Public Domain Dedication waiver (http://creativecommons.org/publicdomain/zero/1.0/) applies to the data made available in this article, unless otherwise stated. 


\section{Specification of the construct Theoretical background}

What MMIs measure is usually described by collective terms such as "non-cognitive variables" [5] and "preprofessionalism" [9]. Each MMI differs in the selection of domains that are subsumed under these general terms. Communication skills, ethical decision making, teamwork, integrity and empathy are examples of domains that are more frequent in the MMI literature [6]. While the term "non-cognitive" is still in use in the MMI literature, Roberts et al. [10] suggested early that MMIs do have a cognitive component.

As Eva et al. [11] pointed out, MMI scores should not be considered as mere representations of traits (i.e. dispositions of a person that are relatively stable over time) because the performance depends on the situation. This "context specificity" was the reasoning behind the multiple sampling approach of the MMI $[5,12]$. The importance of the person-situation interaction is also emphasised in interactionist models of human behaviour such as the trait activation theory in the context of assessment centres $[13,14]$. The key assumption of this theory is that situation trait relevance and situation strength determine whether and how traits are expressed in behaviour. It is expected that variability in trait-expressive behaviour is more likely in situations where trait relevant cues are present and behavioural demands and expectations are ambiguous [13]. In line with the general assumptions of interactionist theories [14], we suggest that verbal responses and observed behaviours at MMI stations are expressions of a complex structure of underlying traits and their interaction with the situation.

\section{The Hamburg MMI}

The MMI at the Hamburg medical school intends to assess psychosocial competencies and is used to select undergraduate medical students. We define "psychosocial competencies" in general as an effective regulation of the self and an effective interaction with others in critical interpersonal situations or when faced with typical problems that medical students and doctors will encounter throughout their career. Three focal domains guide the selection of station content: empathy, communication skills and self-regulation. We described the process that resulted in the selection of these three domains in an earlier publication [15]. The construct does not include clinical skills and it was further decided to exclude scenarios that require ethical reasoning.

We assume that a station score does not represent a candidate's standing on a single domain but rather is a mixture of different domains. However, trait activation theory suggests that the selection of station content based on these three domains would lead to the presence of situational cues that would activate traits in the candidate related to these three domains. Altogether, the score of the
Hamburg MMI is interpreted as a representation of a candidate's psychosocial competencies in situations that predominantly require empathy, communication skills and self-regulation.

\section{Validity claims \\ Convergent validity evidence}

All three of the MMI domains are multi-faceted constructs. A recent overview on empathy from a neuroscientific perspective, for example, proposes that empathy has four key components:

(1) "Affective sharing, the first element of empathy to appear during ontogeny. It reflects the capacity to become affectively aroused by the valence and intensity of others' emotions.

(2) Empathic understanding, which entails the conscious awareness of the emotional state of another person.

(3) Empathic concern, which refers to the motivation to care for someone's welfare.

(4) Cognitive empathy, similar to the construct of perspective taking or theory of mind is the ability to put oneself into the mind of another individual and imagine what that person is thinking or feeling" [16]

Following this definition, emotions and feelings of others play an important role in the empathy construct. Another construct that is closely related to aspects of empathy is emotional intelligence (EI). EI is described as "the ability to perceive and express emotion, assimilate emotion in thought, understand and reason with emotion, and regulate emotion in the self and others" [17], [p. 396]. Based on these definitions, both empathy and emotional intelligence encompass the understanding of emotions and the ability to perceive emotions in others.

If the MMI score is understood as a representation of psychosocial skills with empathy as one of the focal domains, we would expect a positive relationship with a measure of emotional intelligence. Although it plays a dominating role, empathy is not the only construct assessed by the MMI. Furthermore, empathy and emotional intelligence are not identical constructs despite the conceptual overlap. Thus, we assume that the relationship between MMI scores and the EI measure would be small in magnitude.

We know of only one study that analysed the relationship between MMI scores and an EI measure. In that study, the correlation between a self-report measure of $\mathrm{EI}$ and performance at an MMI for selection into allied health programs was non-significant [18]. Additionally, two other studies showed that EI was not related to 
traditional interviews $[19,20]$. However, Libbrecht et al. found that EI correlated with the performance of medical students in practical courses on communication and interpersonal sensitivity which included role-plays with simulated patients [21].

\section{Predictive validity evidence}

The MMI is used for selecting students who will most likely demonstrate good psychosocial competencies in relevant situations throughout their medical career. In order to claim that the MMI fulfils this purpose, evidence is needed that MMI scores predict future behaviour in situations that evoke competencies related to empathy, communication skills and self-regulation.

The curriculum at the Hamburg medical school provides a first opportunity to test this claim after the first year of study. Before the start of the second year, students are required to spend one week with a general practitioner and assist with the daily routines. The general practice (GP) field provides a relevant context because in this field it is crucial that doctors possess good psychosocial competencies [22], perhaps even more than in other areas of the medical profession. General practitioners (GPs) work closely with patients and most patients will come regularly to the same doctor for consultation. Good psychosocial competencies help build trust and a positive doctorpatient relationship. This positive relationship is highly relevant to GPs and patients and leads to positive outcomes [23-25]. For this reason, the second study analyses the GPs' evaluations of the students' psychosocial competencies. We expected a positive correlation between MMI scores and GPs' evaluations. Unlike the standardised setting of the MMI, the experience and situations during the week in the practice can vary from student to student and evoke psychosocial competencies to a different degree. Therefore, we assumed that the relationship would be small to medium in size.

Three studies have reported that performance in an MMI or MMI-like interview procedure could predict evaluations by supervisors or peers during clerkship [26-28]. Similarly, MMIs for the selection into specialty training could predict supervisor ratings of communication skills [29]. However, Burkhardt et al. found that the MMI was not significantly correlated with first-year resident performance when other selection factors were included in the model [30].

The second possibility for analysing the predictive evidence in Hamburg is a standardised OSCE after one and a half years of study. While the OSCE is primarily designed to assess clinical skills, it includes stations in which communication skills are assessed to a varying degree. The MMI and the OSCE in Hamburg are based on the same understanding of good communication skills [31]. We assumed that there would be a small positive correlation between the MMI and OSCE because both intend to measure communication skills to a differing extent. We further expected that there should be a stronger relationship to OSCE stations with a focus on these skills.

The MMI literature so far has reported correlations with OSCE performance or other performance-based exams of $-.05<r<.43[26,32-35]$.

\section{Control variables}

For each of the three studies, we considered age, gender and other selection measures as possible control variables. Both gender and age could be argued to have an influence on psychosocial competencies. There are indications that women perform better on measures of empathy and communication skills; for example, in the context of an OSCE [36]. Research in neuroscience suggests that these differences might have evolutionary explanations [37]. Although the results of studies on gender differences in MMI scores are mixed [8], Ross et al. recently demonstrated an advantage for female applicants in a cumulative meta-analysis at the University of Calgary [38]. In addition, maturity could play a role in the development of psychosocial competencies. Older candidates might have gained more life experience that could help them develop more confidence in psychosocial competencies. Again, the results on the relationship between age and MMI performance are mixed but if a significant relationship is found, it is positive and rather small [8]. Finally, the MMI can only be considered as a useful selection tool if it predicts relevant outcomes over and above the existing selection measures.

\section{Relevance}

Although all three criteria (EI, supervisor ratings, OSCE scores) have already been the subject of previous studies, this is the first study to report validity evidence for a German MMI. Furthermore, the relationship with emotional intelligence has only been analysed in one previous study, which focused on an MMI for selection into allied health sciences programs. This work also provides further insight by concentrating on the GP context as a field in which psychosocial competencies are considered highly relevant. Overall, the accumulated validity evidence for different MMIs suggests that MMIs can be designed to be predictive of relevant outcomes. However, the results are sometimes mixed and they depend on the design of the MMI. More insight is needed regarding the theoretical framework of MMIs and their design that would help to explain why results are sometimes positive and sometimes negative [6]. Therefore, this work provides details regarding the underlying construct and the design of the MMI. We aim to provide information that could be relevant in future comparisons of different MMI approaches and their validity evidence. 


\section{Methods}

\section{Cohort and selection procedure}

In this study, we analysed data from the 2014 admission cohort at the University Medical Center HamburgEppendorf. Forty percent of places at medical schools in Germany are assigned by a centralised agency and based on students' high-school grade point averages (GPA; German: Abitur), waiting time and other criteria. For the other $60 \%$ of places, each university has its own local admission procedure. In Hamburg, candidates were pre-selected based on their GPA and had to write a natural science test (HAM-Nat) [39]. The first 115 candidates in a ranking order based on their GPA and HAM-Nat results were directly rewarded with a study place. The next 200 applicants in the ranking were invited to an MMI [15]. The selection decision was based on the following procedure: GPA values were transformed into a linear 60-point scale, while HAM-Nat and MMI were each transformed into a linear 59-point scale. The sum of these three scores determined the ranking order for the remaining 106 study places. Given that MMI participants were pre-selected by a combination of GPA and HAM-Nat, the range of these two combined factors was small (range: $79-87$ points), which allowed the MMI scores (range: $24-50$ points) to have a stronger impact on the final ranking.

\section{Multiple mini-interview}

The 2014 interviews took place on a single day with four parallel circuits in four consecutive rounds. Candidates rotated through seven stations including three stations with an interviewer and four stations with simulations. The overall performance at each station was evaluated by two raters on a Likert-scale ranging from 1 (very poor) to 5 (very good). The mean over these two ratings was taken to form the station score. A candidate's overall MMI score was then calculated as the mean of all station scores. Raters were medical doctors, psychologists and other employees of the university's medical centre. A 4-h rater training took place one day before the interviews and consisted of a general introduction to the interview procedure as well as station-specific training, which included mock interviews. Raters were provided with detailed descriptions about the station task and a score sheet that listed 9 to 14 behavioural descriptors of a very poor and a very good performance that were structured under three to five station-specific rating categories. Table 1 gives an overview of station tasks including examples of behavioural descriptors related to empathy and communication skills.

\section{Study measures \\ Measures of emotional intelligence (EI)}

Three months after the admission procedure we asked all admitted and rejected candidates of the local selection process to participate in an online study that included two EI measures. As there is an ongoing dispute in the literature regarding the conceptualisation and measurement of EI $[40,41]$, each of the two measures represented one of the two dominant streams within EI research. One measure conceptualises EI as a trait (trait EI) and the other

Table 1 Overview of MMl stations

\begin{tabular}{|c|c|c|c|}
\hline Station number & Type & Main task & $\begin{array}{l}\text { Example of behavioural descriptors on score sheets } \\
\text { related to empathy and communication skills }\end{array}$ \\
\hline 1 & Simulation & $\begin{array}{l}\text { find a balance between one's own interests and } \\
\text { another person's needs and motives }\end{array}$ & $\begin{array}{l}\text { - recognises SP's loneliness and the need for company } \\
\text { - active listening }\end{array}$ \\
\hline 2 & Interview & $\begin{array}{l}\text { respond to a past-behavioural question concerning } \\
\text { a situation in which the candidate felt frustrated }\end{array}$ & $\begin{array}{l}\text { - thinks about possible reasons, motives and feelings of the } \\
\text { other persons involved; coherently justifies his/her thoughts } \\
\text { - structures his/her description }\end{array}$ \\
\hline 3 & Simulation & reject a request of a worried patient & $\begin{array}{l}\text { - demonstrates sympathy for the SP's worries about his/her } \\
\text { partner and for the insecurity of not knowing the diagnosis } \\
\text { - communicates clearly }\end{array}$ \\
\hline 4 & Interview & $\begin{array}{l}\text { describe observations made in a video of an } \\
\text { interaction between a mother and a son }\end{array}$ & $\begin{array}{l}\text { - considers the structure of the relationship between the two } \\
\text { in his/her analysis } \\
\text { - descriptions are precise, [...] to the point }\end{array}$ \\
\hline 5 & Simulation & address a conflict (in a monologue) & $\begin{array}{l}\text { - demonstrates appreciation for the other person (e.g. } \\
\text { empathises positive sides and similarities, expresses wishes, } \\
\text { takes the other person's perspective) } \\
\text { - describes clear motives }\end{array}$ \\
\hline 6 & Simulation & shared-decision making & $\begin{array}{l}\text { - expresses sympathy for feelings (e.g. desire for independence, } \\
\text { disappointment / anger because of family, fear) } \\
\text { - speaks clearly, slowly and comprehensibly }\end{array}$ \\
\hline 7 & Interview & $\begin{array}{l}\text { reflect on and interpret emotional statements } \\
\text { by patients }\end{array}$ & $\begin{array}{l}\text { - names emotions and thoughts } \\
\text { - description is vivid and allows for a good understanding of } \\
\text { the emotional situation }\end{array}$ \\
\hline
\end{tabular}


conceptualises EI as an ability (ability EI). As the trait EI measure relies on self-report items, it is particularly prone to "faking good" tendencies that have been observed in high-stake selection procedures [42, 43]. Therefore, we chose a three-month time lag to ensure that candidates would not associate the questionnaire with the selection process. Participants could win one of ten 50 EUR vouchers for an online bookstore.

Trait Emotional Intelligence Questionnaire Short Form (TEIQue-SF). The TEIQue-SF [44, 45] is a 30-item selfreport questionnaire that measures global trait EI. An example item is "I can deal effectively with people". Participants rate their level of agreement for each item on a scale of 1 (completely disagree) to 7 (completely agree). A validated German translation was available from the test developers $[46,47]$. Previous studies reported internal consistencies of $\alpha>80$ [44, 47]. A recent systematic review summarised that the TEIQue-SF explains incremental variance in criteria such as academic performance and life satisfaction $\left(.01 \leq \Delta R^{2} \leq .18\right)$ over and above higherorder personality dimensions such as the Big Five [48]. In their systematic review for the medical education field, Arora et al. [49] recommended the use of the TEIQue in further EI research because of the good psychometric properties of the test.

Situational Test of Emotion Management (STEM). The STEM [50] measures emotion management, which is one facet of ability EI. It is a situational judgement test (SJT) with 44 scenarios. Each scenario describes an emotional situation (e.g. "Surbhi starts a new job where he doesn't know anyone and finds that no one is particularly friendly.") and includes four possible responses (e.g. "Have fun with his friends outside of work hours." / "Concentrate on doing his work well at the new job."). Test takers are asked to either select the most effective response (multiple-choice) or to rate the effectiveness of each response (rate-the-effectiveness) and their ratings are compared to ratings by subject matter experts [50]. A validated German translation of the STEM was available by Hilger et al. [51]. According to this version, we asked candidates to rate the effectiveness of each response on a scale ranging from 1 (not effective at all) to 6 (very effective). The candidate's final scores were calculated as the mean of the absolute difference from an expert rating for each item. Therefore, small values of the STEM indicate stronger agreement between the participant and the subject matter experts.

Internal consistencies for both formats were reported to be acceptable ( $\alpha=.68$ for multiple-choice, $\alpha=.92$ for rate-the-effectiveness) [50]. Previous studies have demonstrated that the STEM scores do not reflect personality or fluid intelligence $[50,52,53]$. It is related to other performance-based measures of EI but shows low to nonsignificant correlations to self-reported EI [53, 54]. Evidence for the validity of the assumptions of the STEM was further demonstrated by negative correlations with externally oriented thinking and states of distress as well as positive correlations with retrospective life satisfaction, academic achievement and well-being [50, 55]. Most importantly, the STEM could predict performance in courses on communication and interpersonal sensitivity during the first three years of medical school [21].

\section{General practitioners' evaluations}

After the first year of study, all students spend one week with a general practitioner (GP). The major goal of this 1:1 teaching is to introduce at an early stage the students to the GP field. Therefore, students mainly watch and assist when possible. They are also given the opportunity to take patients' histories and perform physical examinations. A few weeks prior, we asked students for their consent to collect data and match it to admission data. Participating students could win one of five 100 EUR vouchers for an online store.

All general practitioners involved in the study were at the time part of a GP teaching program at the university medical centre. Practices can take one or more students but only one student at a time. Some of the GPs took part in an information session. All GPs received a written explanation of the study and instructions on how to complete the questionnaire. For each student, GPs received a letter at the end of the week with three questionnaires. We asked GPs and up to two other members of their practice team who interacted with the student to complete the questionnaire.

A literature research did not identify any existing instrument that was suitable for our study purposes especially considering our aim - which was to focus on psychosocial competencies - and also the limited amount of time that GPs had to complete the questionnaire. Therefore, two of the authors (MK and AS), both psychologists, developed a new questionnaire that was reviewed by a third author (ME) - who is a general practitioner and coordinates the teaching practices program - and a medical student. Two validated instruments in German for the evaluation of encounters with patients provided ideas for relevant rating categories: the Frankfurt Observer Communication Checklist (FrOCK) [56] and the Globalskalen ÄGF-A [57]. As we needed an instrument for evaluating a whole week and with a focus on psychosocial competencies, we left out rating categories that were applicable to only single encounters (e.g. the structure of the conversation) and categories that concentrated on clinical aspects (e.g. history taking). In addition, a student assistant of the admission research group collected accounts of experiences of fellow second year medical students after they had finished their general practice week. Based on these accounts, the student assistant provided a list of possible observable behaviours in encounters with patients and members of 
the practice. We then compared the categories from the literature with the accounts by the students and created five categories under which we structured the behavioural descriptors. The categories were "conversation", "non-verbal communication", "interaction", "work habits" and "professionalism and teamwork" (Additional file 1). Each category was rated on a five-point Likert scale ranging from 1 (very weakly pronounced) to 5 (very well pronounced). In an attempt to draw a connection between the selection context of the MMI and the GP context, we additionally asked the raters to give an evaluation of the suitability of the student for the medical profession on a four-point Likert scale ranging from 1 ("not suitable") to 4 ("absolutely suitable").

\section{OSCE}

Students can register for the first OSCE after one and a half years of study, at the earliest. It consists of twelve stations, which mostly assess basic clinical skills such as measuring blood pressure, interpreting radiographic images, and examining lungs. One of the stations primarily measures communication skills. Learning objectives that are tested at this station include structuring a conversation meaningfully, verbalizing emotions adequately, and paraphrasing the patient's subjective concept of the illness. In addition, two other stations on history taking indirectly rely on communication skills. Common learning objectives that are tested at both of these stations are patient-centred communication and the structure of history taking. Students can receive up to 20 points for each station resulting in a maximum possible overall OSCE score of 240 points. We analysed the correlation between overall MMI score and overall OSCE score and, more specifically, between MMI score and the performance at each of the three communication and history-taking stations.

\section{Statistical analysis}

The statistical analysis was conducted in IBM SPSS Version 21.0.0.0 and $\mathrm{R}$ version 3.4.2 including the packages RVAideMemoire and MASS. For the analysis of our hypotheses, we first calculated all zero-order correlations between MMI performance and the outcome variables. If a significant relationship was found, its stability was further investigated in a regression model for each of the outcomes. To determine which of the possible control variables had to be considered in the model, we analysed whether gender, age, HAM-Nat result and GPA were related to MMI performance or any of the outcomes. The final regression models would then include MMI performance and all relevant control variables as predictors.

\section{Ethics}

The local ethics commission board (Ethik-Kommission der Ärztekammer Hamburg, PV4983) approved this research as not constituting research with human subjects ("kein Forschungsvorhaben am Menschen") in a clinical sense. All students who were included in the analysis gave their written informed consent to collect, match and analyse their admission and study data.

\section{Results \\ Participants}

Table 2 lists the number of candidates in 2014 and the participation rates for each study. Twenty-four percent of the candidates who were invited to the EI online study participated and provided a full dataset, including $35 \%$ of candidates who underwent the MMI. These were 38 out of 106 candidates who were admitted by the MMI and 31 out of 90 candidates who were rejected after the MMI.

At the time of the GP study, 281 out of 385 students (73\%) were registered for a general practice and agreed to participate. The response rate by the practices was 77\% (217 out of 281). Finally, GP study data from 195 participants could be matched to the 2014 admission data including 59 students who undertook the MMI (56\% of all who were admitted after the MMI). In two cases, raters did not provide a suitability rating.

OSCE data was available for 301 students who had already gained the required study achievements and who had registered for the exam in 2016. Out of these, 89 had MMI performance data $(84 \%$ of all who were admitted after the MMI).

\section{Descriptive statistics}

We observed high means and negative skewness for all variables except for the STEM, which is the only variable where lower values signify better performance (Table 3 ). In addition, Shapiro-Wilk tests suggested that normality cannot be assumed for any of the variables. The descriptive statistics indicated that small sample sizes, deviations from the normal distribution and the presence of outliers required statistical methods that were robust against these conditions. Therefore, Spearman's rank correlation was used to analyse the relationship between two variables and Wilcoxon rank-sum tests to analyse group differences.

The reliability of each measure was determined using Cronbach's alpha for internal consistencies, intraclass correlations for interrater reliability and a mixed model approach for the overall generalisability of the MMI result. A detailed description of this approach can be found in an earlier publication [15]. The overall reliability of the MMI was .65 and the overall interrater agreement was ICC $=.68$. Both values are within the range of what is typically reported in the MMI literature [6]. Cronbach's alpha values for both of the EI measures were $>.80$. The internal consistency for the five social competency items in the GP study was very high $(\alpha=.94)$. Therefore, we 
Table 2 Number of candidates/study participants, mean age at each time point and gender for total 2014 cohort and respective study, including time of data collection

\begin{tabular}{|c|c|c|c|c|}
\hline & Total cohort (09/2014) & Study $1(12 / 2014)$ & Study 2 (10/2015) & Study 3 (09/2016) \\
\hline & Admission process & El online & GP evaluations & OSCE \\
\hline \multicolumn{5}{|l|}{ Admitted } \\
\hline Central agency quota $(N)$ & 164 & - & 76 & 115 \\
\hline HAM-Nat quota (N) & 115 & 41 & 60 & 97 \\
\hline MMl quota $(N)$ & 106 & 38 & 59 & 89 \\
\hline Age $(M / S D)$ & $22.6 / 4.9$ & $20.8 / 2.1$ & $23.0 / 3.9$ & $23.4 / 3.5$ \\
\hline Gender (percentage male) & $39.7 \%$ & $43.0 \%$ & $36.4 \%$ & $40.9 \%$ \\
\hline \multicolumn{5}{|l|}{ Rejected } \\
\hline HAM-Nat quota $(N)$ & 720 & 137 & - & - \\
\hline MMl quota $(N)$ & 90 & 31 & - & - \\
\hline Age $(M / S D)$ & $20.3 / 1.8$ & $20.6 / 2.2$ & - & - \\
\hline Gender (percentage male) & $32.2 \%$ & $28.6 \%$ & - & - \\
\hline
\end{tabular}

$N=$ number of students, $M=$ mean, $S D=$ standard deviation

$\mathrm{EI}=$ emotional intelligence, $\mathrm{GP}=$ general practice, $\mathrm{OSCE}=$ objective structured clinical examination, HAM-Nat = Hamburg natural science test,

$\mathrm{MMI}=$ multiple mini-interview

used the mean of these five items over one to three raters ("GP psychosocial competencies rating") as the outcome measure for the study. The second outcome measure was an evaluation of the suitability for the medical profession ("GP suitability rating") over one to three raters. Both outcome measures showed enough variability to allow for a cautious comparison to admission data. The raters of the GP study were medical doctors (63.8\%), medical assistants (30.9\%) and practice team members of other professions (1.3\%). Four percent of the raters did not make any statement concerning their profession. Wilcoxon rank-sum tests showed that ratings by practices of physicians who were present at the information session $(25 \%$ of participating practices) did not differ significantly from ratings by practices that did not attend (GP psychosocial skills: $\mathrm{W}=52,608, p>.05 ; \mathrm{GP}$ suitability: $\mathrm{W}=24,720.5$, $p>.05)$. Finally, the internal consistency of the OSCE stations was $\alpha=.53$.

Table 3 Descriptive statistics and reliability values for study measures

\begin{tabular}{|c|c|c|c|c|c|c|c|}
\hline & N & M & SD & Min / Max & Skewness & Shapiro-Wilk Test & Reliability \\
\hline MMl & 196 & 3.63 & .47 & $2.38 / 4.69$ & -.35 & $W=0.99, p<.05$ & Overall $=.65^{\mathrm{a}}: \mathrm{ICC}=.68$ \\
\hline \multicolumn{8}{|l|}{ Study 1: } \\
\hline Global Trait Emotional Intelligence (TEIQue-SF) & 247 & 5.38 & .62 & $3.57 / 6.63$ & -.51 & $W=0.98, p<.001$ & $a=.86$ \\
\hline Emotion Management (STEM) & 247 & 1.11 & .23 & $.71 / 2.38$ & 1.59 & $W=0.90, p<.001$ & $a=.94$ \\
\hline \multicolumn{8}{|l|}{ Study 2: } \\
\hline GP psychosocial competencies & 195 & 4.53 & .72 & $1.00 / 5.00$ & -2.46 & $W=0.68, p<.01$ & $a=.94^{b}: I C C=.88 / .92^{b}$ \\
\hline GP suitability & 193 & 3.71 & .54 & $1.00 / 4.00$ & -2.20 & $W=0.60, p<.01$ & $I C C=.73 / .61^{c}$ \\
\hline \multicolumn{8}{|l|}{ Study 3: } \\
\hline OSCE & 301 & 199.65 & 10.17 & 164 / 221 & -1.13 & $W=0.93, p<.001$ & $a=.53^{\mathrm{d}}$ \\
\hline
\end{tabular}

$N=$ number of students, $M=$ mean, $S D=$ standard deviation, $\operatorname{Min} /$ Max = minimum and maximum value, $a=$ Cronbach's Alpha, ICC = intraclass correlation for interrater reliability

$\mathrm{MMI}=$ multiple mini-interview, TEIQue-SF $=$ Trait Emotional Intelligence Questionnaire Short Form, STEM = Situational Test of Emotion Management, GP = general practitioner, OSCE = objective structured clinical examination

${ }^{a}$ Overall reliability was estimated by means of a mixed-model. See Hissbach, et al. [15] for more details on the formula

${ }^{b}$ Alpha refers to the internal consistency of five items. ICCs refer to the interrater-agreement for the average measure of the five items in cases of two raters (first value, $n=53$ ) and in cases of three raters per subject (second value, $n=74$ )

'Interrater-agreement for one item in cases of two raters (first value, $n=51$ ) and in cases of three raters per subject (second value, $n=74$ )

${ }^{c}$ Alpha refers to the internal consistency of twelve station scores 


\section{Control variables}

There was a small but significant correlation between age and MMI result $(\rho=.16, p<.05)$. Age was also significantly related to GP psychosocial skills $(\rho=.17$, $p<.05)$ as well as GP suitability $(\rho=.23, p<.01)$. A Wilcoxon rank-sum test revealed a significant difference in MMI scores for gender $(\mathrm{W}=5781, p<0.01)$ with female candidates scoring higher $(\mathrm{Md}=3.74)$ than male candidates $(\mathrm{Md}=3.55)$. No significant gender differences were found for any of the outcome variables. Neither GPA nor HAM-Nat performance was related to MMI or any of the outcome variables (Additional file 2).

\section{Correlations between MMI performance and outcome measures}

Neither global trait EI nor emotion management (ability EI) correlated with MMI results (Table 4). However, MMI results correlated significantly with GP psychosocial competencies $(\rho=.32, p<.05)$, GP suitability $(\rho=.42, p<.01)$ and OSCE score $(\rho=.23, p<.05)$. While the confidence interval for both the correlation with GP psychosocial competencies as well as OSCE score had a lower bound close to zero, this value was higher for the correlation with GP suitability $\left(\mathrm{CI}_{\text {lowerbound }}=.17\right)$. There were no significant correlations between MMI score and specific scores on the three OSCE stations, which directly or indirectly focus on communication skills (communication: $\rho=.14$, $p>.05,95 \%$ CI: $-.07 / .34$; history taking $1: \rho=.02, p>.05$, 95\% CI: $-.20 / .22$; history taking $2: \rho=.13, p>.05,95 \%$ CI: $-.08 / .34)$.

\section{Robustness of the results}

In a final step, we analysed whether the positive correlation between MMI and GP psychosocial skills, GP suitability and OSCE overall score would be sustained when controlling for the identified relevant control variables of gender and age. For this analysis, we used robust regression models with an $\mathrm{M}$ estimator. Robust regression is advisable if the assumptions of linear regressions are violated, particularly in the case of outliers [58]. The robust regression models for each of the three outcomes showed that the MMI remained a significant predictor when the control variables were part of the model. Both gender and age were non-significant predictors in each of the models (Table 5).

\section{Discussion}

The growing implementation of resource-intensive MMIs into the admission procedures of medical schools around the globe demonstrates that the psychosocial competencies of future medical students are highly valued. Evidence that MMIs really measure these competencies is still needed $[4,6]$. We hypothesised that if the MMI scores could be interpreted as measures of psychosocial competencies with empathy as one of the focal domains, there would be a positive relationship between MMI performance and EI. However, we did not find a significant correlation with either of the EI measures.

We replicated the finding by Yen et al. [24] that MMI performance does not correlate with a self-report measure of EI. Although we administered the questionnaire three months after the admission process, it might be that candidates still felt the need to present themselves favourably. It is known that self-ratings generally tend to be inflated and influenced by leniency and social desirability biases [59]. Moreover, "faking good" in personality measures is a well-observed phenomenon in the context of medical school selection [42, 43]. If self-perceptions of emotion related competencies did not match observer perceptions, this could explain the missing relationship.

However, we also could not find a positive correlation with emotion management. The STEM is a performance-

Table 4 Spearman's rank correlation between MMI and study measures

\begin{tabular}{llll}
\hline 1. MMI & $\begin{array}{l}\text { 2. Trait El } \\
\text { (TEIQue-SF) }\end{array}$ & $\begin{array}{l}\text { 3. Emotion } \\
\text { Management } \\
\text { (STEM) }\end{array}$ & $\begin{array}{l}\text { 4. GP psychosocial } \\
\text { competencies }\end{array}$ \\
\end{tabular}

Study 1:

$\begin{array}{ll}\text { 2. Trait El (TEIQue-SF) } & .07(-.19 / .30), n=69 \\ \text { 3. Emotion Management (STEM) } & .05(-.17 / .27), n=69 \quad .16^{*}(.03 / .28), n=247\end{array}$

Study 2:

4. GP psychosocial competencies $.32 *(.04 / .55), n=59-.14(-.43 / .15), n=44 \quad-.07(-.38 / .25), n=44$

5. GP suitability $\quad .42^{* *}(.17 / .64), n=58 \quad-.15(-.42 / .15), n=44 \quad .01(-.31 / .36), n=44 \quad .71^{* *}(.62 / .79), n=193$

Study 3:

6. OSCE $.23^{*}(.03 / .41), n=89 \quad .12(-.13 / .34), n=67 \quad-.06(-.30 / .19), n=67 \quad .08(-.08 / .24), n=181 \quad .15(-.002 / .29), n=180$

${ }^{*} p<.05, * * 0<.01$

$95 \%$ confidence interval in parentheses

$M M I=$ multiple mini-interview, El = emotional intelligence, TEIQue-SF = Trait Emotional Intelligence Questionnaire Short Form, STEM $=$ Situational Test of Emotion

Management, GP = general practice, $O S C E$ = objective structured clinical examination 
Table 5 Robust regression analyses including control variables

\begin{tabular}{llllll}
\hline Dependent variable & Independent variable & $b$ & SE & $t$ & $d f$ \\
\hline GP psychosocial skills & MMl & 0.53 & 0.20 & $2.67^{*}$ & 54 \\
& gender & -0.12 & 0.11 & -1.06 & 54 \\
\multirow{5}{*}{ GP suitability } & age & 0.01 & 0.04 & 0.15 & 54 \\
& MMl & 0.65 & 0.17 & $3.77^{* *}$ & 53 \\
OSCE overall score & gender & -0.11 & 0.10 & -1.11 & 53 \\
& age & 0.001 & 0.03 & 0.06 & 53 \\
& gender & 7.05 & 3.46 & $2.04^{*}$ & 85 \\
& age & -2.29 & 1.98 & -1.15 & 85 \\
& & 0.005 & 0.58 & 0.01 & 85 \\
\hline
\end{tabular}

* $p<.05, * * p<.01$

$b=$ robust regression coefficient, $S E=$ standard error, $d f=$ degrees of freedom $M M I=$ multiple mini-interview,$G P=$ general practitioner,$O S C E=$ objective structured clinical examination

based measure of EI in which a person's response is compared to responses by experts. This measure thereby puts an emphasis on the perspective of others on emotional intelligent behaviour, similar to raters in an MMI. It could be that emotion management in particular is too narrow a construct for the broad construct of psychosocial competencies that we want to measure in our MMI. If we look for commonalities between the definitions of empathy and emotional intelligence, both rely on understanding emotions and the ability to perceive emotions in others. One could argue that perceiving and understanding emotions are necessary for effectively managing emotions. However, we suggest further exploration of this matter and advise that future studies consider alternative ability EI measures such as the Mayer-Salovey-Caruso Emotional Intelligence Test (MSCEIT) [60], which includes subtests related to the perception and understanding of emotions. Finally, our finding could also be due to a methodological artefact of the response format. Many of the published validity studies on the STEM relied on the multiple-choice format [21, 53-55], although the rate-the-extent format is superior in reliability [50]. We decided to use the rate-theextent format of the German version because it provides more information than the multiple-choice format. There is no clear explanation yet for the difference between the response formats [50]. If further studies on the relationship between MMI performance and the STEM are conducted, it is advisable to take both response formats into account.

In line with our expectation, MMI results correlated with ratings of psychosocial competencies in a GP context. This finding supports the intended use of the MMI to select medical students who will demonstrate psychosocial competencies in relevant contexts. However, the finding is preliminary and there are some weaknesses in this study. We did not have the opportunity to provide all of the raters with intensive training as a means to make sure that the frame of reference was the same for every rater. This could explain why ratings were in general very favourable. Both MMI scores and GPs' evaluations were based on observational ratings. Although we provided instruction and objective rating criteria in both cases, subjective impressions surely played an additional role in both rating processes. The GP suitability ratings were even conceptualised as an overall subjective impression. Looking at the confidence intervals, the relationship between MMI scores and GP suitability ratings seems more trustworthy than the relationship between MMI scores and GP ratings of psychosocial skills. This could mean that the positive correlation between MMI scores and GP ratings are due rather to similar subjective impressions than similar objective rating criteria. A further limitation of this study is the use of a newly developed questionnaire rather than a validated measure. We could not find a previously validated tool that would fit our purpose of concentrating on psychosocial competencies only. We worked closely with GPs and medical students who had already spent a week in a general practice to make sure that the questionnaire was tailored to the conditions and possibilities of the GP week.

This study replicates findings that MMI performance predicts OSCE performance. Yet our expectation that this relationship should be stronger for stations that focus on communication skills was not supported. It is possible that the MMI assesses a more subjective impression of general good communication skills while the OSCE communication station more strongly focuses on the objective evaluation of the correct application of communication techniques in a physician-patient interaction that are taught in medical school. We assumed that OSCE history taking stations indirectly assess communication skills but the indirect effect on these stations' scores might have been too small. Overall, the OSCE puts an emphasis on clinical skills that were not assessed in the MMI. Therefore, the correlation between MMI and OSCE could be due to similar, more general competencies that are required to handle an exam situation well [33]. However, the lower bound of the correlation between MMI and OSCE score was close to zero which indicates that this correlation has to be interpreted with caution.

There are three general limitations to this study. First, we had drop-out rates for all three studies. Only MMI participants who were admitted could participate in the GP and OSCE studies. The response rates for the MMI subgroup in these studies were acceptable (GP study: $56 \%$, OSCE study: $84 \%$ ). However, while we were able to invite admitted and rejected MMI participants to the EI online study, only $35 \%$ of them responded to the questionnaire. Given that the questionnaire was administered online the lower response rate is not surprising and is comparable to similar studies $[61,62]$. Second, results are impaired by range restriction [63] because candidates 
with low MMI values were not admitted. However, this limitation most likely weakens the correlations between MMI performance and GP ratings or OSCE scores. It is therefore probable that the actual correlations are even higher. Moreover, range restriction could also be one reason for the non-association between MMI results and OSCE communication stations. The third general limitation is that we only analysed one cohort at one medical school over the course of two years. Further follow-up studies are under way in which we will analyse whether our findings are robust over cohorts and for later time points. Multi-centre studies based on the same MMI would allow to further test the generalisability of evidence regarding the validity of the MMI.

\section{Conclusion}

In this study, we inspected three criteria that we expected to be related to MMI performance. The strongest association was found in a practical context with the evaluation of students' suitability for the medical profession. Here, the medical students worked in a multi-professional team and formed initial relationships with real patients without the pressure of an exam. The Hamburg MMI was not developed to primarily predict good performance at exams or personality tests, but rather to predict behaviour in a real-life professional context. Therefore, this finding provides preliminary support for the assumption that we can generalize from the behaviour in the MMI context to a professional context where psychosocial competencies are very relevant. Future validation studies need to investigate further associations with desired outcome criteria, particularly with regard to patients' perceptions of the medical student. While we could find predictive validity evidence for the Hamburg MMI, it remains uncertain whether the claim that MMI scores represent psychosocial competencies as defined in the introduction holds true. The results indicate that more elaboration on a comprehensive theory for psychosocial competencies and the MMI as an assessment tool is necessary.

\section{Additional files}

Additional file 1: Appendix 1, Research questionnaire, English translation of the questionnaire which was developed for the general practice study (DOCX $30 \mathrm{~kb}$ )

Additional file 2: Appendix 2, Tests for control variables, Statistical analyses of the relationship between the control variables (gender, age, GPA and HAM-Nat) and study variables (MMI and outcome measures) (DOCX $14 \mathrm{~kb})$

\section{Abbreviations}

El: Emotional intelligence; GP: General practice; GPA: Grade point average; HAM-Nat: Hamburg natural science test; MMI: Multiple mini-interview; OSCE: Objective structured clinical examination; STEM: Situational Test of Emotion Management; TEIQue-SF: Trait Emotional Intelligence Questionnaire

\section{Acknowledgements}

The authors would like to thank Hubertus Meyer for his contributions to the development of the general practice questionnaire and Kerstin Schrom for her assistance in organizing the data collection for the general practice study.

\section{Funding}

This project was funded by the Federal Ministry of Education and Research in Germany (BMBF), funding code 01PL12033. The responsibility for the content of this publication lies with the publishers and authors.

\section{Availability of data and materials}

The datasets used and/or analysed during the current study are available from the corresponding author on reasonable request.

\section{Authors' contributions}

MK, AS, ME and WH all contributed to conception and the design of the work. MK, AS, JL and SZ were responsible for the data acquisition. MK analyzed the data and drafted the manuscript. All authors revised the manuscript critically and approved of the final version for publication.

\section{Authors' information}

Dipl.-Psych. Mirjana Knorr is a psychologist with a special interest in work and organizational psychology. She is a researcher and PhD student at the University Medical Centre Hamburg-Eppendorf. Her PhD thesis focuses on reliability and validity aspects of the Hamburg multiple mini-interview for the selection of medical students.

Dipl.-Psych. Anja Schwibbe is a psychologist with experiences in different personnel selection areas. She is a researcher at the University Medical Centre Hamburg-Eppendorf. Her research interests are mainly in the domains of development and validation of selection tests, with a special focus on situational judgment tests.

Dr. med. Maren Ehrhardt is a general practitioner and works at the Institute of General Practice/primary care at the University Medical Centre Hamburg Eppendorf. She is involved in the improvement and accomplishment of the old and new (iMED) undergraduate curriculum and the teaching program in primary care.

Dipl.-Psych. Janina Lackamp is a psychologist and PhD student at the University Medical Centre Hamburg-Eppendorf. Her research interests center mainly on undergraduate student selection with a focus on empathy and its measurement. She is doing her clinical training in psychodynamic psychotherapy.

Stefan Zimmermann, MSc, works on the application of statistical methods in educational psychology. He is a researcher at the University Medical Centre Hamburg-Eppendorf and a PhD student at the University of Bamberg. Recent research focused on validity of a reading test and the test security in a science test.

Wolfgang Hampe, PhD, is professor for biochemistry at the University Medical Centre Hamburg-Eppendorf. He has completed a Master's degree in Medical Education and is responsible for the development and implementation of the student admission tests.

\section{Ethics approval and consent to participate}

The local ethics commission board (Ethik-Kommission der Ärztekammer Hamburg, PV4983) approved this research as not constituting research with human subjects ("kein Forschungsvorhaben am Menschen") in a clinical sense. All students who were included in the analysis gave their written informed consent to collect, match and analyse their admission and study data.

\section{Competing interests}

The authors declare that they have no competing interests.

\section{Publisher's Note}

Springer Nature remains neutral with regard to jurisdictional claims in published maps and institutional affiliations.

\section{Author details}

'Department of Biochemistry and Molecular Cell Biology, University Medical Center Hamburg-Eppendorf (UKE), N30, Martinistraße 52, 20246 Hamburg, Germany. ${ }^{2}$ Department of General Practice / Primary Care, University Medical Center Hamburg-Eppendorf (UKE), W37, Martinistraße 52, 20246 Hamburg, Germany. 


\section{Received: 8 June 2017 Accepted: 20 April 2018}

\section{Published online: 14 May 2018}

\section{References}

1. Frank JR, Snell L, Sherbino J, editors. CanMEDS 2015 physician competency framework. Ottawa: Royal College of Physicians and Surgeons of Canada; 2015

2. Koenig TW, Parrish SK, Terregino CA, Williams JP, Dunleavy DM, Volsch JM. Core personal competencies important to entering students' success in medical school: what are they and how could they be assessed early in the admission process? Acad Med. 2013;88:603-13.

3. Lambe P, Bristow D. What are the most important non-academic attributes of good doctors? A Delphi survey of clinicians. Med Teach. 2010;32:e347-e54.

4. Patterson F, Knight A, Dowell J, Nicholson S, Cousans F, Cleland J. How effective are selection methods in medical education? A systematic review. Med Educ. 2016;50:36-60.

5. Eva KW, Rosenfeld J, Reiter HI, Norman GR. An admissions OSCE: the multiple mini-interview. Med Educ. 2004;38:314-26.

6. Knorr M, Hissbach J. Multiple mini-interviews: same concept, different approaches. Med Educ. 2014;48:1157-75.

7. Pau A, Jeevaratnam K, Chen YS, Fall AA, Khoo C, Nadarajah VD. The multiple mini-interview (MMI) for student selection in health professions training - a systematic review. Med Teach. 2013;35:1027-41.

8. Rees EL, Hawarden AW, Dent G, Hays R, Bates J, Hassell AB. Evidence regarding the utility of multiple mini-interview (MMI) for selection to undergraduate health programs: a BEME systematic review: BEME guide no. 37. Med Teach. 2016;38:443-55.

9. Roberts C, Walton M, Rothnie I, Crossley J, Lyon P, Kumar K, Tiller D. Factors affecting the utility of the multiple mini-interview in selecting candidates for graduate-entry medical school. Med Educ. 2008;42:396-404.

10. Roberts C, Zoanetti N, Rothnie I. Validating a multiple mini-interview question bank assessing entry-level reasoning skills in candidates for graduate-entry medicine and dentistry programmes. Med Educ. 2009;43:350-9.

11. Eva KW, Reiter HI, Trinh K, Wasi P, Rosenfeld J, Norman GR. Predictive validity of the multiple mini-interview for selecting medical trainees. Med Educ. 2009;43:767-75.

12. Eva KW. On the generality of specificity. Med Educ. 2003;37:587-8.

13. Lievens F, De Koster L, Schollaert E. Current theory and practice of assessment centers: the importance of trait activation. In: Cartwright $S_{\text {, }}$ Cooper $\mathrm{CL}$, editors. The Oxford handbook of personnel psychology. Oxford: Oxford University Press; 2008. p. 215-33.

14. Lievens F, Schollaert E, Keen G. The interplay of elicitation and evaluation of trait-expressive behavior: evidence in assessment center exercises. J Appl Psychol. 2015;100:1169-88.

15. Hissbach JC, Sehner S, Harendza S, Hampe W. Cutting costs of multiple mini-interviews - changes in reliability and efficiency of the Hamburg medical school admission test between two applications. BMC Med Educ. 2014:14:1-10.

16. Decety J, Fotopoulou A. Why empathy has a beneficial impact on others in medicine: unifying theories. Front Behav Neurosci. 2014:8:457.

17. Mayer JD, Salovey P, Caruso D. Models of emotional intelligence. In: Sternberg R, editor. Handbook of intelligence. Cambridge, UK: Cambridge University Press; 2000. p. 396-420.

18. Yen W, Hovey R, Hodwitz K, Zhang S. An exploration of the relationship between emotional intelligence (EI) and the multiple mini-interview (MMI). Adv Health Sci Educ Theory Pract. 2011;16:59-67.

19. Leddy JJ, Moineau G, Puddester D, Wood TJ, Humphrey-Murto S. Does an emotional intelligence test correlate with traditional measures used to determine medical school admission? Acad Med. 2011:86:S39-41.

20. Carr SE. Emotional intelligence in medical students: does it correlate with selection measures? Med Educ. 2009:43:1069-77.

21. Libbrecht N, Lievens F, Carette B, Cote S. Emotional intelligence predicts success in medical school. Emotion. 2014;14:64-73.

22. Patterson F, Tavabie A, Denney M, Kerrin M, Ashworth V, Koczwara A, MacLeod S. A new competency model for general practice: implications for selection, training, and careers. Br J Gen Pract. 2013;63:e331-8.

23. Sans-Corrales M, Pujol-Ribera E, Gené-Badia J, Pasarín-Rua MI, Iglesias-Pérez B, Casajuana-Brunet J. Family medicine attributes related to satisfaction, health and costs. Fam Pract. 2006;23:308-16.

24. Derksen F, Bensing J, Lagro-Janssen A. Effectiveness of empathy in general practice: a systematic review. Br J Gen Pract. 2013;63:e76-84.
25. Kearley KE, Freeman GK, Heath A. An exploration of the value of the personal doctor-patient relationship in general practice. Br J Gen Pract. 2001;51:712-8.

26. Reiter HI, Eva KW, Rosenfeld J, Norman GR. Multiple mini-interviews predict clerkship and licensing examination performance. Med Educ. 2007:41:378-84.

27. Hadad A, Gafni N, Moshinsky A, Turvall E, Ziv A, Israeli A. The multiple mini-interviews as a predictor of peer evaluations during clinical training in medical school. Med Teach. 2016:38:1172-9.

28. Meredith KE, Dunlap MR, Baker HH. Subjective and objective admissions factors as predictors of clinical clerkship performance. J Med Educ. 1982;57:743-51.

29. Bindal T, Wall D, Goodyear HM. Performance of paediatric senior house officers following changes in recruitment. Med Teach. 2007;29:501-3.

30. Burkhardt JC, Stansfield RB, Vohra T, Losman E, Turner-Lawrence D, Hopson $L R$. Prognostic value of the multiple mini-interview for emergency medicine residency performance. J Emerg Med. 2015;49:196-202.

31. Bachmann C, Abramovitch H, Barbu CG, Cavaco AM, Elorza RD, Haak R, et al. A European consensus on learning objectives for a core communication curriculum in health care professions. Patient Educ Couns. 2013:93:18-26.

32. Eva KW, Reiter HI, Rosenfeld J, Norman GR. The ability of the multiple miniinterview to predict preclerkship performance in medical school. Acad Med. 2004;79:S40-2.

33. Husbands A, Dowell J. Predictive validity of the Dundee multiple miniinterview. Med Educ. 2013;47:717-25.

34. Kelly ME, Dowell J, Husbands A, Newell J, O'Flynn S, Kropmans T, et al. The fairness, predictive validity and acceptability of multiple mini interview in an internationally diverse student population- a mixed methods study. BMC Med Educ 2014:14:267.

35. Lee HJ, Park SB, Park SC, Park WS, Ryu SW, Yang JH, et al. Multiple miniinterviews as a predictor of academic achievements during the first 2 years of medical school. BMC Res Notes. 2016;9:93.

36. Graf J, Smolka R, Simoes E, Zipfel S, Junne F, Holderried F, et al. Communication skills of medical students during the OSCE: gender-specific differences in a longitudinal trend study. BMC Med Educ. 2017;17:75.

37. Christov-Moore L, Simpson EA, Coude G, Grigaityte K, lacoboni M, Ferrari PF. Empathy: gender effects in brain and behavior. Neurosci Biobehav Rev. 2014;46(Pt 4):604-27.

38. Ross M, Walker I, Cooke L, Raman M, Ravani P, Coderre S, McLaughlin K. Are female applicants rated higher than males on the multiple mini-interview? Findings from the University of Calgary. Acad Med. 2017;92:841-6.

39. Hissbach JC, Klusmann D, Hampe W. Dimensionality and predictive validity of the HAM-Nat, a test of natural sciences for medical school admission. BMC Med Educ 2011:11:1-11.

40. Cherniss C. Emotional intelligence: toward clarification of a concept. Ind Organ Psychol. 2010;3:110-26.

41. Cherry MG, Fletcher I, O'Sullivan H, Dornan T. Emotional intelligence in medical education: a critical review. Med Educ. 2014:48:468-78.

42. Griffin B, Wilson I. Faking good: self-enhancement in medical school applicants. Med Educ. 2012:46:485-90.

43. Yusoff MSB. Faking good in personality and emotional intelligent tests: selfenhancement among a cohort of medical school applicants. Education in Medicine Journal. 2013;5:e60-71.

44. Petrides KV, Furnham $\mathrm{A}$. The role of trait emotional intelligence in a gender-specific model of organizational variables. J Appl Soc Psychol. 2006:36:552-69.

45. Petrides KV. Psychometric properties of the trait emotional intelligence questionnaire (TEIQue). In: Stough C, Saklofske DH, Parker JD, editors. Assessing emotional intelligence: theory, research, and applications. New York: Springer; 2009. p. 85-101.

46. Freudenthaler $\mathrm{HH}$, Neubauer AC, Gabler $\mathrm{P}$, Scherl WG, Rindermann $\mathrm{H}$. Testing and validating the trait emotional intelligence questionnaire (TEIQue) in a German-speaking sample. Pers Individ Dif. 2008;45:673-8.

47. Jacobs I, Sim C-W, Zimmermann J. The German TEIQue-SF: factorial structure and relations to agentic and communal traits and mental health. Pers Individ Dif. 2015;72:189-94.

48. Andrei F, Siegling AB, Aloe AM, Baldaro B, Petrides KV. The incremental validity of the trait emotional intelligence questionnaire (TEIQue): a systematic review and meta-analysis. J Pers Assess. 2016;98:261-76.

49. Arora S, Ashrafian H, Davis R, Athanasiou T, Darzi A, Sevdalis N. Emotional intelligence in medicine: a systematic review through the context of the ACGME competencies. Med Educ. 2010;44:749-64. 
50. MacCann C, Roberts RD. New paradigms for assessing emotional intelligence: theory and data. Emotion. 2008;8:540-51.

51. Hilger L, Hellwig S, Schulze R. Deutschsprachige Adaptation des STEU sowie des STEM und erste Validitätsevidenz. In: 48th conference of the German Society for Psychology. Bielefeld: German Psychological Society (DGPs); 2012.

52. MacCann C. Further examination of emotional intelligence as a standard intelligence: a latent variable analysis of fluid intelligence, crystallized intelligence, and emotional intelligence. Pers Individ Dif. 2010;49:490-6.

53. Libbrecht $N$, Lievens F. Validity evidence for the situational judgment test paradigm in emotional intelligence measurement. Int J Psychol. 2012;47:438-47.

54. Austin EJ. Measurement of ability emotional intelligence: results for two new tests. Br J Psychol. 2010;101:563-78.

55. Burrus J, Betancourt A, Holtzman S, Minsky J, MacCann C, Roberts RD. Emotional intelligence relates to well-being: evidence from the situational judgment test of emotional management. Appl Psychol Health Well Being 2012:4:151-66

56. Sennekamp M, Gilbert K, Gerlach FM, Guethlin C. Development and validation of the "FrOCK": Frankfurt observer communication checklist. Z Evid Fortbild Qual Gesundhwes. 2012;106:595-601.

57. Preusche I. Ärztliche Gesprächsführung A. In: Frischenschlager O, HladschikKermer B, editors. Gesprächsführung in der Medizin: lernen, lehren, prüfen. Wien: Facultas; 2013. p. 241-6.

58. Huber PJ. Robust statistics. New York: Wiley; 1981.

59. Atwater $L E$, Yammarino FJ. Does self-other agreement on leadership perceptions moderate the validity of leadership and performance predictions? Pers Psychol. 1992;45:141-64.

60. Mayer JD, Salovey P, Caruso DR, Sitarenios G. Measuring emotional intelligence with the MSCEIT V2.0. Emotion. 2003;3:97-105.

61. Sax L, Gilmartin SK, Bryant AN. Assessing response rates and nonresponse bias in web and paper surveys. Res High Educ. 2003;44:409-32.

62. Manfreda KL, Bosniak M, Berzelak J, Haas I, Vehovar V. Web surveys versus other survey modes - a meta-analysis comparing response rates. Int J Mark Res. 2008;50:79-104.

63. Sackett PR, Yang H. Correction for range restriction: an expanded typology. J Appl Psychol. 2000;85:112-8.

\section{Ready to submit your research? Choose BMC and benefit from:}

- fast, convenient online submission

- thorough peer review by experienced researchers in your field

- rapid publication on acceptance

- support for research data, including large and complex data types

- gold Open Access which fosters wider collaboration and increased citations - maximum visibility for your research: over $100 \mathrm{M}$ website views per year 